\title{
Hospital outcome and predictors of operative mortality in redo MVR adult population
}

\author{
Ahmed Abdelgawad ${ }^{1 *}$, Alsayed Salem ${ }^{2}$ and Ahmed Elshemy ${ }^{2}$ \\ ${ }^{1}$ Cardiac Surgery Department, Madinah Cardiac Center, Kingdom Saudi Arabia \\ ${ }^{2}$ Cardiac Surgery Department, National Heart Institute, Cairo, Egypt
}

\begin{abstract}
Background: The operative mortality associated with redo heart valve surgery is higher than that of the primary operation 1 . this study aimed to scrutinize the overall hospital morbidity and mortality of adult patients undergoing redo-mitral valve replacement (redo-MVR) at our hospital and identify predictors of operative death and prolonged hospital stay.

Methods: This is a retrospective observational study that included all patients $(n=96)$ who underwent redo-MVR with either bioprosthetic or mechanical valves between January 2012 and December 2017 at Madinah cardiac center, Kingdom of Saudi Arabia. Patients were excluded if they had undergone alternative MV intervention without replacement. Their data were retrieved from the prospectively maintained electronic database.

Results: In this study, the mean age of the whole cohort was [48.66 \pm 12.71$]$ years (range 19-79 years) and the mean additive EuroSCORE was $11 \pm 3$. Median time to re-operation was $[7.87 \pm 3.20$ years] ranging $(2-16$ years) for first-time redo-MVR and $[6.80 \pm 2.86]$ years ranging $3-10$ years for second-time redo-MVR. Indications included prosthetic endocarditis 42 pts (43.8\%), para-prosthetic leak 23 pts (24\%), structural valve degeneration 18 pts (18.8\%) and prosthetic valve thrombosis 14 pts (14.6\%). In-hospital mortality was 11 pts (11.5\%). Mean hospital stay was [12.68 \pm 4.97$]$ days (range 6-24 days). Univariate analysis showed that operative mortality was associated with the $\mathrm{LVEF}<50 \%(\mathrm{P}=0.016)$, structural valve degeneration $(\mathrm{p}<0.001)$ and total operative time in hours $(\mathrm{p}=0.015)$. Similarly, univariate analysis for prolonged hospital stay showed a significant association between it and higher preoperative EuroSCORE ( $\mathrm{p}=0.04)$.
\end{abstract}

Conclusion: Repeat-MVR can be done safely and with a good overall outcome. We insist on early intervention before ventricular dysfunction occurs with its deleterious effects on the outcome of the redo surgery.

\section{Introduction}

The operative mortality associated with redo heart valve surgery is higher than that of the primary operation [1]. Significant advances in prosthesis design, surgical techniques, approaches and perioperative care had been made since the fifties of this century to improve redo surgery outcomes [2].

Although mitral valve repair is better than replacement, MVR is still required in the first operation if the repair is not feasible or in repeat valve surgery. Moreover, improved survival necessitated that more and more mitral patients become in need for repeat valve operations for a multiplicity of reasons such as structural valve degeneration, thrombosis, endocarditis and paravalvular leaks. However, there is some evidence now that clinical outcomes after repeat-valve surgery have improved which highlights the progress in this area [3]. Studies that investigate the operative morbidity and mortality, survival and freedom from re-intervention of patients undergoing redo-MVR with current techniques and prostheses are thus needed [4]. Of note, it is important to identify the peri-operative variables that are associated with poor outcome in order to offer patients the most appropriate interventions. This study reports a single centre's experience with redoMVR in adult patients and aims to identify factors that contribute to poor outcome.

\section{Methods}

\section{Patient population}

This is a retrospective observational study included all patients $(n=$ 96) who underwent redo-MVR with either bioprosthetic or mechanical valves between January 2012 and December 2017 at Madinah cardiac, Kingdom of Saudi Arabia. Patients were excluded if they had undergone alternative MV intervention without replacement (e.g. MV repair, mitral valvuloplasty, open or closed mitral commissurotomy) in the past. Their data were retrieved from the prospectively maintained electronic database. The pathologic state of the valve was obtained from operative and pathologic reports.

\section{Surgical technique}

On-table transoesophageal echocardiography was used routinely from 2005. Surgery was undertaken through a redo-median sternotomy

Correspondence to: Ahmed Abelgawad, Associate Consultant Cardiac Surgery, Madinah Cardiac Center, Kingdom Saudi Arabia, Tel: 00996549567842; E-mail: a_ewais@yahoo.com

Key words: predictor, mortality, repeat, mitral, outcome

Received: January 31, 2018; Accepted: February 20, 2018; Published: February 23,2018 
and cardiopulmonary bypass (CPB) was established with - cannulation. Where there was a close proximity of the sternum to the heart evidenced by lateral CXR or CT chest, CPB was established electively via the -femoral route or the femoral vessels were at least exposed before redosternotomy. Myocardial protection comprised both antegrade and retrograde cold blood cardioplegia and moderate hypothermia $\left(32^{\circ} \mathrm{C}\right)$. Concomitant AVR was performed before MVR, while concomitant TVR was performed after MVR. The left atrium (LA) was opened after developing the inter-atrial groove. The old mitral valve prosthesis was taken, and annulus was debrided. Partial preservation of mitral valve apparatus (leaving posterior valve leaflet intact) was routinely done with enough space for at least $25-\mathrm{mm}$ valve size. A mechanical or bioprosthetic valve was then inserted with horizontal mattress $2 / 0$ Ethibond sutures. Sutures were placed from LA to LV.

\section{Statistical analysis}

Recorded data were analyzed using the statistical package for social sciences, version 20.0 (SPSS Inc., Chicago, Illinois, USA). Quantitative data were expressed as mean \pm standard deviation (SD). Qualitative data were expressed as frequency and percentage.

\section{The following tests were done:}

- Independent-samples t-test of significance was used when comparing between two means.

- Chi-square $\left(\mathrm{X}^{2}\right)$ test of significance was used in order to compare proportions between two qualitative parameters.

- The confidence interval was set to $95 \%$ and the margin of error accepted was set to $5 \%$. So, the p-value was considered significant as the following:

- Probability (P-value)

- P-value $<0.05$ was considered significant.

- P-value $<0.001$ was considered as highly significant.

- P-value $>0.05$ was considered insignificant.

\section{Results}

Table 1 demonstrates the demographic criteria of the study group. In this study, the mean age of the whole cohort was [48.66 \pm 12.71 ] years (range 19-79 years) and the group consisted of 50 (52.1\%) females and 46 (47.9\%) males. The mean additive EuroSCORE was $11 \pm 3$. (30.2\%) of the study group had LV dysfunction with $\mathrm{EF}<50 \%, 60$ patients (62.5\%)in this study had mechanical valves at first time MVR versus 36 patients (37.5\%) who had tissue valves. whereas the most common indication for redo surgery in our series $(43.8 \%)$ was the prosthetic valve endocarditis, the least one (14.6\%) was prosthetic valve thrombosis. Patients had only AVR and TVR as concomitant procedures with first MVR, (20.8\%), (9.4\%) respectively, were included and CABG patients at first MVR were excluded. As far as haemodynamic presenting pathology is concerned, the majority of our patients had (64.6\%) mitral regurgitation followed by stenosis (15.6\%) and then mixed lesions (15.6\%).

The operative data are shown in table 2. (44.8\%) of the study group was done electively, (40.6\%) was done urgently, and (14.6\%) was done emergently. Cardiopulmonary bypass time mean $(\mathrm{m})$ was $[127.03 \pm$ 37.93] with a range of $80-180 \mathrm{~m}$, while Cross-clamp time mean $(\mathrm{m})$ was [92.65 \pm 20.81$]$ with a range of $60-120 \mathrm{~m}$. Total operative time in hours was [7.47 \pm 2.28$]$ with a range of 5-12 h. We did AVR, AVR+TVR, TVR and CABG at the time of redo MVR as concomitant procedures [(30.2\%), (7.3\%), (24.0\%) and (5.2\%) respectively]. [27.85 \pm 2.09 ] was
Table 1. Demographic critertia of the study group

\begin{tabular}{|c|c|}
\hline & Total $(\mathrm{N}=96)$ \\
\hline \multicolumn{2}{|l|}{ Sex } \\
\hline Female & $50(52.1 \%)$ \\
\hline Male & $46(47.9 \%)$ \\
\hline Age (years) & $19-79[48.66 \pm 12.71]$ \\
\hline LVEF $<\mathbf{5 0} \%$ & $29(30.2 \%)$ \\
\hline Mean additive EuroSCORE & $11 \pm 3$ \\
\hline \multicolumn{2}{|l|}{ Previous MVR } \\
\hline Once & $91(94.8 \%)$ \\
\hline Twice & $5(5.2 \%)$ \\
\hline \multicolumn{2}{|l|}{ Type of prosthesis at last MVR } \\
\hline Bioprosthetic & $36(37.5 \%)$ \\
\hline Mechanical & $60(62.5 \%)$ \\
\hline \multicolumn{2}{|l|}{ Time to re-operation } \\
\hline First time redo-MVR & $2-16[7.87 \pm 3.20]$ \\
\hline Second time redo-MVR & $3-10[6.80 \pm 2.86]$ \\
\hline \multicolumn{2}{|c|}{$\begin{array}{l}\text { Concomitant procedures performed at } \\
\text { the time of } 1^{\text {st }} \text { MVR }\end{array}$} \\
\hline AVR & $20(20.8 \%)$ \\
\hline TVR & $9(9.4 \%)$ \\
\hline \multicolumn{2}{|l|}{ Indications for re-operation } \\
\hline Prosthetic valve endocarditis & $42(43.8 \%)$ \\
\hline Paravalvular leak & $23(24 \%)$ \\
\hline Structural valve degeneration & $18(18.8 \%)$ \\
\hline Prosthetic valve thrombosis & $14(14.6 \%)$ \\
\hline \multicolumn{2}{|l|}{ Haemodynamic pathology } \\
\hline Mitral regurgitation & $62(64.6 \%)$ \\
\hline Mitral stenosis & $15(15.6 \%)$ \\
\hline Mixed & $10(10.4 \%)$ \\
\hline
\end{tabular}

LVEF: left ventricular ejection fraction, EuroSCORE: European System for Cardiac Operative Risk Evaluation. MVR: Mitral valve replacement, AVR: aortic valve replacement, TVR: tricuspid valve replacement. Data are presented as mean $\pm \mathrm{SD}$ or as number and percentage.

Table 2. The operative data of the study group

\begin{tabular}{|l|l|}
\hline \multicolumn{1}{|c|}{} & Total (N=96) \\
\hline Priority of surgery & \\
\hline Elective & $43(44.8 \%)$ \\
\hline Urgent & $39(40.6 \%)$ \\
\hline Emergency & $14(14.6 \%)$ \\
\hline Total operative time (h) & $5-12[7.47 \pm 2.28]$ \\
\hline Cardiopulmonary bypass time (m) & $80-180[127.03 \pm 37.93]$ \\
\hline Cross-clamp time (m) & $60-120[92.65 \pm 20.81]$ \\
\hline $\begin{array}{l}\text { Concomitant procedures performed at } \\
\text { the time of redo MVR }\end{array}$ & \\
\hline AVR & $29(30.2 \%)$ \\
\hline TVR & $23(24.0 \%)$ \\
\hline AVR+TVR & $7(7.3 \%)$ \\
\hline CABG & $5(5.2 \%)$ \\
\hline Median prosthesis size (mm) & $25-31[27.85 \pm 2.09]$ \\
\hline Type of prosthesis at redo MVR & \\
\hline Bioprosthetic (\%) & $29(30.2 \%)$ \\
\hline Mechanical (\%) & $66(68.8 \%)$ \\
\hline
\end{tabular}

CABG: coronary artery bypass grafting, Data are presented as mean $\pm \mathrm{SD}$ or as number and percentage.

the mean prosthesis size of the implnated mitral valve. (30.2\%) of our patients had tissue valves compared to $(68.8 \%)$ mechanical valves.

The early postoperative outcome is portrayed in table 3 where the hospital mortality in our series reached (11.5\%). (5.2\%) of our patients were explored for bleeding, $(14.6 \%)$ had permanent pacemaker implantation, (8.3\%) had renal failure necessitating haemofiltration 
Table 3. Early postoperative outcome of the study group

\begin{tabular}{|l|l|}
\hline & Total $(\mathbf{N}=\mathbf{9 6})$ \\
\hline Hospital mortality (\%) & $11(11.5 \%)$ \\
\hline Re-exploration for bleeding & $5(5.2 \%)$ \\
\hline Sepsis & $17(17.7 \%)$ \\
\hline AF & $29(30.2 \%)$ \\
\hline Permanent pacemaker & $14(14.6 \%)$ \\
\hline Haemofiltration & $8(8.3 \%)$ \\
\hline Cerebrovascular event & $6(6.3 \%)$ \\
\hline Mean Hospital Stay (d) & $6-24[12.68 \pm 4.97]$ \\
\hline
\end{tabular}

Data are presented as mean \pm SD or as number and percentage.

and stroke rate was (6.3\%). Mean hospital stay ranged between 6-24 days with a mean of [12.68 \pm 4.97$] \mathrm{d}$.

The univariate analysis was done for both hospital mortality and prolonged hospital stay defined as more than 10 days in this study. All preoperative as well as operative data were taken into the univariate model in both Table 4 and 5. In Table 4, we found a significant association between hospital mortality and $\mathrm{LVEF}<50 \%(\mathrm{P}=0.016)$, structrucal valve degeneration $(\mathrm{p}<0.001)$ and total operative time in hours $(\mathrm{p}=0.015)$. Causes of death included cardiac $(n=3)$, cerebrovascular accident $(n$ $=3)$, sepsis $(n=2)$, pneumonia $(n=2)$ and multi-organ dysfunction $(n=1)$. Similarly, the univariate analysis for prolonged hospital stay was portrayed in table 5 where a significant association between it and higher preoperative EuroSCORE $(\mathrm{p}=0.04)$.

\section{Comment}

Despite the fact that recent years brought a substantial amelioration of repeat valve surgery results in terms of both clinical and functional outcomes, repeat valve surgery is a challenge [3]. It is also quiet conceivable that patients who had MVR are surviving longer and, therefore, they will need more redo operations due to prosthesis failure or valve-related complications. Consequently, we can expect a rise in the number of redo valve operations. Studies which provide information about clinical and functional outcomes of this type of surgery are therefore required to enrich the surgical knowledge of the aramentarium of cardiac surgeons facing this problem as well as improving patients' outcome [4].

Generally speaking, prosthetic valves' complications can be divided into structural valvular degeneration, non-structural dysfunction, valve thromboembolic complications, bleeding and endocarditis [5-7]. For the most common indications for the redo operation in our series, it was endocarditis (43.8\%) which contrasts Jignesh [8] findings who reported pannus formation as the most common cause in $61(94 \%)$ patients. Others reported pannus formation followed by perivalvular leakage, endocarditis and thrombosis or thromboembolism as the most common causes [5-7]. Other investigators reported paravalvular leak as the most common cause for redo surgeries for mechanical prosthesis [9]. Although thrombosis has been directly linked to anti-coagulation use, a direct relationship with the intensity of anti-coagulation had not been proved by some studies [10].

In agreement with our finding, Vohra et al in 2012 [4] found that endocarditis was the most common cause of repeat mitral valve surgery. In our study, it was (43.8\%) versus $60 \%$ for mechanical valves and $29 \%$ for bioprosthetic valves whereas in his study, it was much $>6 \%$ that what had been reported in the literature $[11,12]$. Sturctural valve degeneration occurred in (18.8\%) of our patients ranking third in indications for reoperation which can be attributed to improvements in valve technology, manufacturing and design. Similarly, Others such as
Tyers and collegueas had found that endocarditis was a more frequent cause of re-operation in patients with mechanical when compared with bioprosthetic valves [13].

As far as hospital mortality and factors influencing it are concerned, there are reports of up to $30 \%$ mortality in the literature that now declined to $5-6 \%[5-7,14]$. higher figures were also linked to female gender, higher NHYA class, and emergency operation. Jignesh and associates found that redo surgeries for valve thrombosis with NYHA class of I to II compared favourably with routine redo operations (10\%) whereas valve thrombosis with haemodynamic instability and / or higher NYHA class had significantly higher mortality (45\%) [15].

It is important to bear in mind that on the interpretation of the studies reporting hospital mortality for redo valve surgeries that theses do not usually discriminate between the anatomical position of the valve, with results regularly being mixed for aortic, mitral and tricuspid valve replacements [16-18]. Another factor to consider is that some studies had also included patients who previously underwent MV procedures other than replacement (e.g. MV repair and mitral

Table 4. Univariate analysis for in hospital mortality.

\begin{tabular}{|c|c|c|c|c|}
\hline \multirow{2}{*}{ Parameters } & \multicolumn{2}{|c|}{ In-hospital mortality (\%) } & \multirow[t]{2}{*}{$\mathbf{x} 2 / \mathbf{t} \#$} & \multirow[t]{2}{*}{ p-value } \\
\hline & No $(N=85)$ & Yes $(=11)$ & & \\
\hline \multicolumn{5}{|l|}{ Demographic characteristics } \\
\hline \multicolumn{5}{|l|}{ Sex } \\
\hline Female & $46(54.1 \%)$ & $4(36.4 \%)$ & \multirow{2}{*}{1.230} & \multirow{2}{*}{0.267} \\
\hline Male & $39(45.9 \%)$ & $7(63.6 \%)$ & & \\
\hline Age (years) & $38.32 \pm 12.67$ & $41.27 \pm 13.32$ & $0.524 \#$ & 0.471 \\
\hline LVEF $<50 \%$ & $22(75.8 \%)$ & $7(24.1 \%)$ & 6.58 & 0.016 \\
\hline Previous MVR Once & $81(95.3 \%)$ & $10(90.9 \%)$ & 0.379 & 0.538 \\
\hline Twice & $4(4.7 \%)$ & $1(9.1 \%)$ & 0.379 & 0.538 \\
\hline Bioprosthetic & $33(38.8 \%)$ & $3(27.3 \%)$ & 0.554 & 0.457 \\
\hline Mechanical & $52(61.2 \%)$ & $8(72.7 \%)$ & 0.554 & 0.457 \\
\hline First time redoMVR & $7.98 \pm 3.32$ & $7.00 \pm 1.89$ & $0.823 \#$ & 0.367 \\
\hline Second time redoMVR & $7.75 \pm 2.22$ & $3.00 \pm 0.00$ & $3.671 \#$ & 0.151 \\
\hline $\begin{array}{l}\text { Concomitant procedures } \\
\text { performed at the time of } \\
\text { previous MVR AVR }\end{array}$ & $17(20.0 \%)$ & $3(27.3 \%)$ & 0.312 & 0.576 \\
\hline TVR & $7(8.2 \%)$ & $2(18.2 \%)$ & 1.134 & 0.287 \\
\hline Prosthetic valve endocarditis & $38(44.7 \%)$ & $4(36.4 \%)$ & 0.275 & 0.600 \\
\hline Paravalvular leak & $22(25.9 \%)$ & $1(9.1 \%)$ & 1.507 & 0.220 \\
\hline Structural valve degeneration & $12(14.1 \%)$ & $6(54.5 \%)$ & 10.449 & $<0.001$ \\
\hline Prosthetic valve thrombosis & $13(15.3 \%)$ & $1(9.1 \%)$ & 0.301 & 0.583 \\
\hline $\begin{array}{l}\text { Haemodynamic pathology } \\
\text { Mitral regurgitation }\end{array}$ & $53(62.4 \%)$ & $9(81.8 \%)$ & 1.613 & 0.204 \\
\hline Mitral stenosis & $15(17.6 \%)$ & $0(0.0 \%)$ & 2.301 & 0.129 \\
\hline Mixed & $10(11.8 \%)$ & $0(0.0 \%)$ & 1.445 & 0.229 \\
\hline \multicolumn{5}{|l|}{ Operative data } \\
\hline Elective & $39(45.9 \%)$ & $4(36.4 \%)$ & 0.357 & 0.550 \\
\hline Urgent & $34(40.0 \%)$ & $5(45.5 \%)$ & 0.120 & 0.729 \\
\hline Emergency & $12(14.1 \%)$ & $2(18.2 \%)$ & 0.129 & 0.719 \\
\hline Total operative time & $7.25 \pm 2.18$ & $9.80 \pm 2.17$ & $6.263 \#$ & 0.015 \\
\hline Cardiopulmonary bypass time & $125.38 \pm 37.88$ & $139.82 \pm 37.59$ & $1.418 \#$ & 0.237 \\
\hline Crossclamp time & $93.12 \pm 20.89$ & $88.70 \pm 20.72$ & $0.400 \#$ & 0.529 \\
\hline Concomitant procedures AVR & $26(30.6 \%)$ & $3(27.3 \%)$ & 0.051 & 0.822 \\
\hline TVR & $21(24.7 \%)$ & $2(18.2 \%)$ & 0.228 & 0.633 \\
\hline AVR+TVR & $6(7.1 \%)$ & $1(9.1 \%)$ & 0.059 & 0.807 \\
\hline CABG & $5(5.9 \%)$ & $0(0.0 \%)$ & 0.683 & 0.409 \\
\hline Median prosthesis size & $27.85 \pm 2.06$ & $27.91 \pm 2.43$ & $0.009 \#$ & 0.927 \\
\hline Bioprosthetic (\%) & $26(30.6 \%)$ & $3(27.3 \%)$ & 0.051 & 0.822 \\
\hline Mechanical (\%) & $58(68.2 \%)$ & $8(72.7 \%)$ & 0.091 & 0.762 \\
\hline
\end{tabular}

\#t- Independent Sample t-test; $\mathrm{x}^{2}$ - Chi-square test

p-value $<0.05$ significant; $p$-value $>0.05$ non-significant 
Table 5. Univariate analysis for in prolonged hospital stay $>10$ days

\begin{tabular}{|c|c|c|c|c|}
\hline \multirow[t]{2}{*}{ Parameters } & \multicolumn{2}{|c|}{$\begin{array}{l}\text { Prolonged hospital stay } \\
>10 \text { days }\end{array}$} & \multirow[t]{2}{*}{$\mathbf{x} 2 / \mathbf{t} \#$} & \multirow[t]{2}{*}{ p-value } \\
\hline & Yes $(\mathrm{N}=56)$ & No $(\mathrm{N}=39)$ & & \\
\hline \multicolumn{5}{|l|}{ Demographic characteristics } \\
\hline \multicolumn{5}{|l|}{ Sex } \\
\hline Female & $27(48.2 \%)$ & $23(59.0 \%)$ & \multirow{2}{*}{1.068} & \multirow{2}{*}{0.301} \\
\hline Male & $29(51.8 \%)$ & $16(41.0 \%)$ & & \\
\hline Age (years) & $40.29 \pm 14.53$ & $36.72 \pm 9.18$ & $1.837 \#$ & 0.179 \\
\hline Euro Score & $12.11 \pm 3.23$ & $10.02 \pm 2.14$ & 3.195\# & 0.044 \\
\hline LVEF $<50 \%$ & $20(35.7 \%)$ & $9(23.1 \%)$ & 1.731 & 0.188 \\
\hline Previous MVR Once & $53(94.6 \%)$ & $37(94.9 \%)$ & 0.002 & 0.961 \\
\hline Twice & $3(5.4 \%)$ & $2(5.1 \%)$ & 0.002 & 0.961 \\
\hline Bioprosthetic & $21(37.5 \%)$ & $15(38.5 \%)$ & 0.009 & 0.924 \\
\hline Mechanical & $35(62.5 \%)$ & $24(61.5 \%)$ & 0.009 & 0.924 \\
\hline First time redo-MVR & $8.08 \pm 3.03$ & $7.38 \pm 3.26$ & 1.079\# & 0.302 \\
\hline Second time redo-MVR & $8.67 \pm 1.53$ & $4.00 \pm 1.41$ & $11.76 \#$ & 0.042 \\
\hline $\begin{array}{l}\text { Concomitant procedures } \\
\text { performed at the time of } \\
\text { previous MVR AVR }\end{array}$ & $12(21.4 \%)$ & $7(17.9 \%)$ & 0.174 & 0.677 \\
\hline TVR & $5(8.9 \%)$ & $4(10.3 \%)$ & 0.047 & 0.828 \\
\hline Prosthetic valve endocarditis & $26(46.4 \%)$ & $15(38.5 \%)$ & 0.595 & 0.441 \\
\hline Paravalvular leak & $13(23.2 \%)$ & $10(25.6 \%)$ & 0.074 & 0.786 \\
\hline Structural valve degeneration & $12(21.4 \%)$ & $5(12.8 \%)$ & 1.159 & 0.282 \\
\hline Prosthetic valve thrombosis & $7(12.5 \%)$ & $7(17.9 \%)$ & 0.543 & 0.461 \\
\hline $\begin{array}{l}\text { Haemodynamic pathology } \\
\text { Mitral regurgitation }\end{array}$ & $33(58.9 \%)$ & $28(71.8 \%)$ & 1.656 & 0.198 \\
\hline Mitral stenosis & $10(17.9 \%)$ & $5(12.8 \%)$ & 0.439 & 0.508 \\
\hline Mixed & $6(10.7 \%)$ & $4(10.3 \%)$ & 0.005 & 0.943 \\
\hline \multicolumn{5}{|l|}{ Operative data } \\
\hline Elective & $25(44.6 \%)$ & $17(43.6 \%)$ & 0.01 & 0.919 \\
\hline Urgent & $24(42.9 \%)$ & $15(38.5 \%)$ & 0.184 & 0.668 \\
\hline Emergency & $7(12.5 \%)$ & $7(17.9 \%)$ & 0.543 & 0.461 \\
\hline Total operative time & $7.61 \pm 2.36$ & $7.23 \pm 2.18$ & $0.383 \#$ & 0.539 \\
\hline Cardiopulmonary bypass time & $126.70 \pm 39.02$ & $128.08 \pm 37.14$ & $0.03 \#$ & 0.863 \\
\hline Cross-clamp time & $94.78 \pm 20.47$ & $88.73 \pm 20.83$ & $1.906 \#$ & 0.171 \\
\hline Concomitant procedures AVR & $14(25.0 \%)$ & $15(38.5 \%)$ & 1.964 & 0.161 \\
\hline TVR & $16(28.6 \%)$ & $7(17.9 \%)$ & 1.414 & 0.234 \\
\hline AVR+TVR & $4(7.1 \%)$ & $3(7.7 \%)$ & 0.01 & 0.92 \\
\hline CABG & $1(1.8 \%)$ & $4(10.3 \%)$ & 3.308 & 0.069 \\
\hline Median prosthesis size & $27.96 \pm 2.09$ & $27.62 \pm 2.06$ & $0.649 \#$ & 0.423 \\
\hline Bioprosthetic (\%) & $20(35.7 \%)$ & $9(23.1 \%)$ & 1.731 & 0.188 \\
\hline Mechanical (\%) & $35(62.5 \%)$ & $30(76.9 \%)$ & 2.213 & 0.137 \\
\hline
\end{tabular}

\#t- Independent Sample t-test; $\mathrm{x}^{2}$ - Chi-square test

p-value $<0.05$ significant; $p$-value $>0.05$ non-significant

valvuloplasty) $[16,19]$. In our study, hospitaly mortality was $(11.5 \%)$ which is concordant with the recent literature $[3,5,12]$, despite the fact that $66.7 \%$ of our patients had concomitant procedures.

Actually, there are so many factors that can affect hospital mortality which can include preoperative, operative and understandably postoperative factors. Some studies found different mortality figures for repeat valve surgeries such as Jones study in 2001 who reported an overall mortality figure of $8.6 \%$ which compared well with Gillinov [20], Niederhauser [21], and their associates who found an operative mortality of $8.6 \%$ and $8.8 \%$, respectively, and he also found that mortality was higher for those patients requiring reoperation on a prosthetic valve than mitral valve repair or valvuloplasty. Moreover, repair of periprosthetic leak or replacement of the whole valve had a similar surgical risk and therefore mortality was similar for both in mitral or aortic positions. Higher mortality, however, was linked to endocarditis and prosthetic valve thrombosis [5].
In the same study, operative mortality was higher for a mechanical valve compared with a tissue valve for at all valve positions which agrees with the findings of Tyers [13],Magilligan [22], Bortolotti [23]. Nevetheless, there are some authors who found no difference [24,25]. Mortality in patients with concomitant tricuspid valve replacement was also high in the same study which is similar to some authors' findings [26,27]. This can be easily explained by severely compromised right ventricular function. On the other hand, coronary artery disease can have a detrimental effect on the outcome or to be of borderline significance as some authors stated [24,28]. In our study these factors did not have a significant impact on operative mortality.

Sex did not have an effect on the operative mortality in our series, which agrees with the findings of Cohn [28]. This is in contrary to what had been reported by Lytle [24] who found that female gender had an increased mortality risk for redo aortic valve, and Akins [11] who found that male gender had an increased mortality risk for any redo valve surgery at any given position. Again, age was not a significant risk factor in the univariate analysis of our study, but it was significantly associated with increased operative risk in some studies [24] whereas others had not found any [28].

A very acceptable explanation for falling mortality figures of repeat valve surgeries recently, is the advancement of intraoperative and perioperative care. For example, the improvements in valve technology, manufacturing and design, myocardial protection with multidose cardioplegia, improved monitoring facilities in intensive care units and relatively early detection and intervention of valve related complications $[4,5]$.

Some authors also found a correlation between the degree of urgency of the reoperation and operative mortality. Thus Nonelective operation was documented as a predictor of death by Mazzucco [29]. Wei-Guo Ma et al., [30] in 2015 concluded that the high mortality of $28.6 \%$ in emergency patients can be attributed to the poor general conditions, worsened cardiac function and inappropriately sufficient preoperative preparation. Therefore, he suggested that emergency reoperation, being a life saving, can be the only exemption from not preparing the patient properly [30]. In Akins study [6] 38\% of the operations were nonelective and $44 \%$ required another concurrent cardiac procedure, and he concluded that best results were achieved when the valve replacement is done for a failed bioprosthesis electively and without the requirement for concurrent procedures. In several other reports, acute bacterial endocarditis was identified as a predictor of hospital mortality $[19,23,24,29]$. In our series endocarditis was not a significant predictor of hospital mortality.

In agreement with other studies, we found significant postoperative complications after redo-MVR such as supraventricular arrhythmias, sepsis, acute renal failure requiring renal replacement therapy and stroke [4]. This is expected owing to the high-risk profile of our patients giving the fact that $(30.2 \%)$ of them had LV dysfunction as well as mean additive EuroSCORE of $11 \pm 3$. The association of complications with higher additive EuroSCORE was demonstrated by univariate analysis in this study. We also demonstrated that the LVEF $<50 \%$ was an independent predictor of operative death in the short-term. Some authors for that reason recommend early intervention before irreversible myocardial damage and/or deteriorating LV function with their inherent surgical risk [16,31]. Prolonged hospital stay is not well described in the studies investigating redo MVR $[17,19]$. In this study, we had not found any correlation between pre-operative and operative variables and prediction of prolonged hospital stay. It is also 
understandable that this is strongly linked to the early postoperative course and the occurrence of complications.

In some studies, early mortality had been associated with older age $[3,5,18]$, female gender [16], advanced NYHA class [16,19], low left ventricular ejection fraction $(<35)$, increased left ventricular enddiastolic diameter $(>50 \mathrm{~mm})$, pulmonary oedema, urgent operations $[3,16,12]$, concomitant procedures $[5,19]$ and previous myocardial infarction [12]. we found that preoperative impairment of the LVEF remains the most consistent risk factor for early and overall mortality following redo-MVR.

\section{Conclusion}

Repeat-MVR can be done safely and with a good overall outcome. We insist on early intervention before ventricular dysfunction occurs with its deleterious effects on the outcome of the redo surgery.

\section{Limitations}

This study has all the limitations of retrospective nature. The relatively small number of patients and the lack of late follow-up after the reoperation is another factor. In particular, information was not always available about the previous surgical techniques and details of valve prostheses used in initial valve replacement. Details of anticoagulation management after the initial procedure was also not clear, such as the target international normalized ratio (INR) pursued, the frequency of INR measurements and especially the INR values before the occurrence of valve dysfunction.

\section{References}

1. Ibrahim M, O'Kane H, Cleland J, Gladstone D, Sarsam M, et al. (1994) The St. Jude Medical prosthesis. A thirteen-year experience. J Thorac Cardiovasc Surg 108: 221230. [Crossref]

2. Hufnagel CA, Harvey WP, Rabil PJ, McDermott TF (1954) Surgical correction of aortic insufficiency. Surgery 35: 673-683. [Crossref]

3. Jamieson WR, Burr LH, Miyagishima RT, Janusz MT, Fradet GJ, Lichtenstein SV et al. (2003) Reoperation for bioprosthetic mitral structural failure: risk assessment. Circulation 108: 98-102.

4. Vohra H, Whistance R, Roubelakis A, Barlow A, Tsang G, et al. (2012) Outcome after redo-mitral valve replacement in adult patients: a 10-year single-centre experience. Interact CardioVascul Thorac Sur 4: 575-579. [Crossref]

5. Jones JM, O'kane H, Gladstone DJ, Sarsam MA, Campalani G, et al. (2001) Repeat heart valve surgery: risk factors for operative mortality. J Thorac Cardiovasc Surg 122: 913-918. [Crossref]

6. Akins CW, Buckley MJ, Daggett WM, Hilgenberg AD, Vlahakes GJ, et al. (1998) Risk of reoperative valve replacement for failed mitral and aortic bioprostheses. Ann Thorac Surg 65: 1545-1551. [Crossref]

7. de Bruin MJ, Lacquet LK, Skotnicki SH, Vincent JG, van der Meer JJ (1986) Reoperation for prosthetic heart valve replacement. Thorac Cardiovasc Surg 34: 1216. [Crossref]

8. Kothari J, Patel K, Brahmbhatt B, Baria K, Talsaria M, et al. (2016) Redo Mitral Valve Replacement for Prosthetic Valve Thrombosis: Single Center Experience. J Clin Diagn Res 10: PC01-01PC03. [Crossref]

9. Mustapha R, Philip I, Bohm G, Depoix JP, Enguerand D, Debauchez M, et al. (1994) Thromboses of heart valve prostheses: predisposing and prognostic factors based on a study of 41 patients. Ann Cardiol Angeiol Paris 43: 403-407. [Crossref]

10. Saour JN, Sieck JO, Mamo LA, Gallus AS (1990) Trial of different intensities of anticoagulation in patients with prosthetic heart valves. $N$ Engl J Med 322: 428-432. [Crossref]
11. Akins CW, Buckley MJ, Daggett WM, Hilgenberg AD, Vlahakes GJ, Torchiana DF et al. (1998) Risk of reoperative valve replacement for failed mitral and aortic bioprostheses. Ann Thorac Surg 65: 1545-1551. [Crossref]

12. Potter DD, Sundt TM 3rd, Zehr KJ, Dearani JA, Daly RC, et al. (2004) Risk of repeat mitral valve replacement for failed mitral valve prostheses. Ann Thorac Surg 78: 6772. [Crossref]

13. Tyers GF, Jamieson WR, Munro AI, Germann E, Burr LH, et al. (1995) Reoperation in biological and mechanical valve populations: fate of the reoperative patient. Ann Thorac Surg 60: S464-468. [Crossref]

14. Syracuse DC, Bowman Jr FO, Malm JR (1979) Prosthetic valve reoperations. Factors influencing early and late survival. Journal of Thoracic and Cardiovascular Surgery 77: 346 .

15. Kothari J, Patel K, Brahmbhatt B, Baria K, Talsaria M, et al. (2016) Redo Mitral Valve Replacement for Prosthetic Valve Thrombosis: Single Center Experience. J Clin Diagn Res 10: PC01-01PC03. [Crossref]

16. Akay TH, Gultekin B, Ozkan S, Aslim E, Uguz E, et al. (2008) Mitral valve replacements in redo patients with previous mitral valve procedures: mid-term results and risk factors for survival. J Card Surg 23: 415-421. [Crossref]

17. Maganti M, Rao V, Armstrong S, Feindel CM, Scully HE, et al. (2009) Redo valvular surgery in elderly patients. Ann Thorac Surg 87: 521-525. [Crossref]

18. Masri Z, Girardet R, Attum A, Barbie R, Yared I, et al. (1990) Reoperation for prosthetic heart valve dysfunction: 19 years' experience. Tex Heart Inst $J$ 17: 106-111. [Crossref]

19. Piehler JM, Blackstone EH, Bailey KR, Sullivan ME, Pluth JR, et al. (1995) Reoperation on prosthetic heart values. Patient-specific estimates of in-hospital events. J Thorac Cardiovasc Surg 109: 30-48. [Crossref]

20. Gillinov AM, Cosgrove DM, Lytle BW, Taylor PC, Stewart RW, et al. (1997) Reoperation for failure of mitral valve repair. $J$ Thorac Cardiovasc Surg 113: 467-473. [Crossref]

21. Niederhäuser U, Carrel T, von Segesser LK, Laske A, Turina M (1993) Reoperation after mitral valve reconstruction: early and late results. Eur J Cardiothorac Surg 7: 34-37. [Crossref]

22. Magilligan DJ Jr, Oyama C, Alam M (1985) Comparison of dysfunction with mechanical and porcine mitral valve prostheses. Circulation 72: II129-134. [Crossref]

23. Bortolotti U, Milano A, Mossuto E, Mazzaro E, Thiene G, et al. (1994) Early and late outcome after reoperation for prosthetic valve dysfunction: analysis of 549 patients during a 26-year period. J Heart Valve Dis 3: 81-87. [Crossref]

24. Lytle BW, Cosgrove DM, Taylor PC, Gill CC, Goormastic M, et al. (1986) Reoperations for valve surgery: perioperative mortality and determinants of risk for 1,000 patients, 1958-1984. Ann Thorac Surg 42: 632-643. [Crossref]

25. McGrath LB, Fernandez J, Laub GW, Anderson WA, Bailey BM, et al. (1995) Perioperative events in patients with failed mechanical and bioprosthetic valves. Ann Thorac Surg 60: S475-478. [Crossref]

26. Hornick P, Harris PA, Taylor KM (1996) Tricuspid valve replacement subsequent to previous open heart surgery. J Heart Valve Dis 5: 20-25. [Crossref]

27. Glower DD, White WD, Smith LR, Young WG, Oldham HN, et al. (1995) In-hospital and long-term outcome after porcine tricuspid valve replacement. $J$ Thorac Cardiovasc Surg 109: 877-883. [Crossref]

28. Cohn LH, Aranki SF, Rizzo RJ, Adams DH, Cogswell KA, et al. (1993) Decrease in operative risk of reoperative valve surgery. Ann Thorac Surg 56: 15-20. [Crossref]

29. Mazzucco A, Milano A, Mazzaro E, Bortolotti U (1993) Reoperation in patients with a bioprosthesis in the mitral position: indications and early results. J Heart Valve Dis 2: 646-648. [Crossref]

30. Ma W G, Hou B, Abdurusul A, Gong D X, Tang Y, Chang Q, Xu J P, Sun H S Dysfunction of mechanical heart valve prosthesis: experience with surgical managemen in 48 patients. J Thorac Dis. 2015 December; 7(12): 2321-2329. [Crossref]

31. Morishita K, Mawatari T, Baba T, Fukada J, Abe T (1998) Re-replacement for prosthetic valve dysfunction: analysis of long-term results and risk factors. Ann Thorac Surg 65: 696-699. [Crossref]

Copyright: (C2018 Abdelgawad A. This is an open-access article distributed under the terms of the Creative Commons Attribution License, which permits unrestricted use, distribution, and reproduction in any medium, provided the original author and source are credited. 